\title{
Behaviour of aluminium alloy plain and lipped channel columns
}

DOI:

10.1016/j.tws.2018.11.010

\section{Document Version}

Accepted author manuscript

Link to publication record in Manchester Research Explorer

\section{Citation for published version (APA):}

Zhu, J., Li, Z., Su, M., \& Young, B. (2018). Behaviour of aluminium alloy plain and lipped channel columns. ThinWalled Structures, 135, 306-316. https://doi.org/10.1016/j.tws.2018.11.010

\section{Published in:}

Thin-Walled Structures

\section{Citing this paper}

Please note that where the full-text provided on Manchester Research Explorer is the Author Accepted Manuscript or Proof version this may differ from the final Published version. If citing, it is advised that you check and use the publisher's definitive version.

\section{General rights}

Copyright and moral rights for the publications made accessible in the Research Explorer are retained by the authors and/or other copyright owners and it is a condition of accessing publications that users recognise and abide by the legal requirements associated with these rights.

\section{Takedown policy}

If you believe that this document breaches copyright please refer to the University of Manchester's Takedown Procedures [http://man.ac.uk/04Y6Bo] or contact uml.scholarlycommunications@manchester.ac.uk providing relevant details, so we can investigate your claim.

\section{OPEN ACCESS}


Ji-Hua Zhu, Zi-qi Li, Mei-Ni Su and Ben Young, (2019) "Behaviour of Aluminium Alloys Plain and Lipped Channel Columns", Thin-wall structures, 135:306-316.

\title{
Behaviour of Aluminium Alloy Plain and Lipped Channel Columns
}

\author{
Ji-Hua Zhu' ${ }^{1}$ Zi-qi Li ${ }^{1}$, Mei-Ni Su*2 and Ben Young ${ }^{3}$ \\ ${ }^{1}$ Department of Civil Engineering, Shenzhen University, Shenzhen, China \\ 2 *School of Mechanical, Aerospace and Civil Engineering, University of Manchester, Manchester, \\ UK, email: Meini.su@manchester.ac.uk \\ ${ }^{3}$ Department of Civil Engineering, The University of Hong Kong, Pokfulam Road, Hong Kong, \\ China
}

\begin{abstract}
Aluminium alloys have high strength-to-weight ratios and great durability; thus, they have been extensively used in structural applications. Channel sections have a smooth and aesthetically pleasing line shape, good integrity, and are easy to connect. An experimental program using 28 specimens and a numerical study that generated 100 results were conducted on aluminium alloy columns of plain and lipped channel sections. The nominal length of columns ranged from $300 \mathrm{~mm}$ to $3000 \mathrm{~mm}$. The generated 128 results were evaluated with respect to the existing design specifications from America, Australia/New Zealand, Europe and China. Furthermore, the direct strength method (DSM) and the continuous strength method (CSM) were also used to predict results for comparison. The results showed that the design specifications produced conservative compression strengths of aluminium alloy columns of both plain and lipped channel sections. The CSM provided more accurate and consistent design strengths. In addition, the reliability levels of the four international design codes, DSM and CSM for channel sections of aluminium alloy columns were also evaluated.
\end{abstract}

\section{Keywords :}

Aluminium alloys; Buckling; Channel section; Column; Continuous strength method; Direct strength method; Reliability analyses; Structure design

\section{Introduction}

Aluminium alloys have advantageous characteristics (e.g., a high strength-to-weight ratio and great corrosion resistance) and that has led to its wide use in engineering applications. Moreover, the aluminium alloy members can be extruded economically into various sections with different geometries. Among the different possible sections, channel sections have been increasingly applied in construction projects due to their smooth and aesthetically pleasing line shape, good integrity, and are easy to connect. Research of aluminium alloy components has mainly been concentrated on square, rectangular, and circular hollow sections. There have been limited studies on aluminium alloy plain and lipped channel sections, especially for the long columns failed by flexural-torsional buckling.

The axial load capacity of aluminium alloys has been investigated in the past decades. The compressive capacity of aluminium alloys with varying cross-section geometries have been studied by using both experimental and numerical investigations. These studied section shapes include 
square and rectangular hollow sections [1], circular hollow sections [2], channels [3], and angles [4]. Currently, the compression capacity of aluminium alloy columns can be determined according to several design standards, such as the Aluminium Design Manual (AA) [5], the Australia and New Zealand Standards (AS/NZS) [6], Eurocode 9 (EC9) [7] and the Chinese Code for Design of Aluminium Structures (CN) [8]. The compression capacity can also be assessed by the direct strength method (DSM) and the continuous strength method (CSM). Schafer and Peköz [9] firstly proposed the DSM approach for cold-formed steel structural members and included in the North American Specification [10], considering the influences of the global buckling, the coupling effect of the global buckling and local buckling, and the coupling effect of the distortional buckling and component yielding. Later, Zhu and Young $[11,12]$ modified the DSM for designing aluminium alloy columns of square and rectangular hollow sections (SHS/RHS). In 2015, the DSM has been included in the Aluminium Design Manual (AA) [5] to cover the local buckling design for aluminium alloy columns. Recently, Su et al. [13,14] proposed the continuous strength method (CSM), which is a deformation-based design method for the prediction of aluminium alloy compression capacity. The CSM approach provides an opportunity to systematically consider the positive effect of strain hardening for stocky sections.

This paper studies the compressive behaviour of aluminium alloy columns on plain and lipped channel sections. In this study, 28 aluminium alloy columns were tested, including 14 members with a plain channel section and 14 members with a lipped channel section. A numerical model was then built, and its modelling results were compared with the experimental results. Upon validation, numerical simulations were carried out for 100 cases as a parametric study. The design codes from America, Europe, Australia/New Zealand, and China for aluminium alloy structures as well as the DSM and CSM approaches were used to predict design strengths for comparison with the testing results and numerical results. Finally, the design methods were assessed by reliability analysis.

\section{Experimental programme}

\subsection{Specimens}

The experimental program was carried out in the Structural Laboratory of The University of Hong Kong [15]. In this program, a total of 28 aluminium alloy columns, including 14 of plain channel sections and 14 of lipped channel sections, were prepared for testing. The heat-treated aluminium alloys 6061-T6 and 6063-T5 were extruded to fabricate these 28 specimens. The section length varied between 300 to $3000 \mathrm{~mm}$. The material properties of aluminium alloys were measured by tensile coupon tests. Table 1 and Table 2 present the cross-sectional dimensions and material properties of plain and lipped channel test specimens, respectively. The tested material stress - strain curves of aluminium alloys T5 and T6 are shown in Fig. 1.

The specimens were labelled according to "section shape - strength - nominal length - (repeated testing or not)". For instance, using the specimen "P-T5-L1350\#" as an example, the "P" represents that it is a plain channel section; if " $\mathrm{P}$ " is replaced with " $\mathrm{L}$ " here, then the lipped channel section would be represented. "T5" represents the normal strength aluminium alloy 6063-T5; if "T5" is replaced with "T6", then the high strength aluminium alloy 6061-T6 would be represented. The "L1350" is the specimen's nominal length (mm). If a symbol "\#" follows the nominal length, the specimen is a repeated test for the given condition. 


\subsection{Compression tests}

A servo-controlled hydraulic testing machine was used to apply compressive axial force to the specimen. Fig. 2 presents the compression test configuration for long columns. In the test setup, both ends of aluminium alloy are fixed. A rigid bearing plate was bolted to the end supports to restrain the axis rotations (minor and major), twist rotations and warping. Hence, the rigid bearing was considered to be a fixed-ended bearing, and a special bearing was used at the lower end support. The details of tests can be found in our previous studies [15].

End plates are commonly welded to both ends of column specimens to apply compressive force. However, heat-treated aluminium alloys suffer loss of strength in a localized region when welding is involved, and this is well known as heat-affected zone (HAZ) softening. Although the HAZ is limited to a small region -1 inch $(25.4 \mathrm{~mm})$ to either side of the centre of a weld according to the AA (2015) - it reduces the column strength significantly. Therefore, the column specimens in this test program were connected with the end plates using bolt connections through the angle plates and stiffen plates which were placed along the outside and inside perimeters of the cross section, as shown in Fig 3. Hence, the HAZ softening was avoided throughout the column tests.

Initially, the top end plate of the specimen was bolted to the rigid bearing plate. The load was then applied at the upper end through the rigid bearing plate. The ram of the actuator was moved slowly until the special bearing was in full contact with the bottom end plate of the specimen, having a small initial load of approximately $1 \mathrm{kN}$. This procedure would eliminate any possible gaps between the special bearing and the bottom end plate of the column, since the special bearing was free to rotate in any direction. The bottom end plate of the specimen was then bolted to the special bearing, and the bearing was prevented from twisting or rotating by using horizontal and vertical bolts, respectively. Hence, the special bearing became a fixed-ended bearing and the column specimens were considered as fixed-ended columns.

Three displacement transducers were used to measure the axial shortening of the specimens. Displacement control was used to drive the hydraulic actuator at a constant speed of $0.1 \mathrm{~mm} / \mathrm{min}$. The use of displacement control allowed the tests to be continued into the post-ultimate range. A data acquisition system was used to record the applied load and readings from the three displacement transducers at regular intervals during the tests.

\subsection{Measured Overall Geometric Imperfections}

Initial overall geometric imperfections were measured on all specimens prior to testing, except for the short specimens of $300 \mathrm{~mm}$ in length. The overall geometric imperfection measurements comprised the flexural imperfections about the minor $y$-axes of the plain and lipped channel section specimens. After the specimen was properly positioned in the test rig, an axial force of approximately $1 \mathrm{kN}$ was applied to hold the specimen in place. A theodolite was then used to obtain readings at the mid-length and near both ends of the specimens. The geometric imperfections were measured near the plate junction of the plain and lipped channel specimens. The measured overall geometric imperfections at mid-length about the $y$-axis $\left(\delta_{y}\right)$ normalized with respect to the specimen length $(L)$ are shown in Table 3. The maximum measured overall geometric imperfections at the mid-lengths were 1/1138, 1/917, 1/1069 and 1/1217 of the specimen length for Series P-T5, P-T6, L-T5 and L-T6, respectively. 


\subsection{Results}

Tables 4 and 5 present the ultimate loads $\left(P_{E x p}\right)$ and corresponding failure modes as measured from the experimental testing. It is shown that the failure modes varied with the length of the column. The failure modes included local buckling, the interaction of local and flexural buckling, and a combination of local, flexural, and flexural-torsional buckling. Please be noted that typo is identified in [15] regarding to the reported failure modes. The corrected failure modes are presented in Tables 4 and 5 herein.

For columns with the plain channel section, short columns (lengths of $300 \mathrm{~mm}$ and $800 \mathrm{~mm}$ ) failed by local buckling. The medium columns (lengths of $1350 \mathrm{~mm}$ and $1900 \mathrm{~mm}$ ) failed by local and flexural buckling. Long columns (lengths of $2450 \mathrm{~mm}$ and $3000 \mathrm{~mm}$ ) failed by a combination of local buckling, flexural buckling and flexural-torsional buckling.

For columns with the lipped channel section, specimens failed by local buckling for short columns of specimen lengths $300 \mathrm{~mm}$ and $800 \mathrm{~mm}$. The medium columns of specimen lengths 1350 $\mathrm{mm}$ and $1900 \mathrm{~mm}$ failed by both local and flexural-torsional buckling. Different from the plain channel sections, the long columns (lengths of $2450 \mathrm{~mm}$ and $3000 \mathrm{~mm}$ ) of lipped channel section failed by flexural buckling only.

\section{Numerical Analyses}

The finite element (FE) program ABAQUS [16] was used for numerical simulation in this study. A parametric study was then carried out to examine the effects of key geometry parameters on the compressive strength of the normal-strength and high-strength aluminium alloy columns with plain and lipped channel sections. The studied parameters included effective length, width-to-thickness ratio, and slenderness ratio. The numerical results from the parametric study in this section are used in the following section to evaluate the predictions based on the existing design methods.

\subsection{FE model validation}

The FE model employed the S4R general-purpose shell elements with the experimentally measured material properties. The element sizes in the FE models of plain and lipped channel sections were $10 \times 10 \mathrm{~mm}^{2}$ and $5 \times 5 \mathrm{~mm}^{2}$, respectively. The measured dimensions and initial geometric imperfections of the specimens were used in the FE models. The fixed-ended boundary condition was simulated by restraining all the degrees of freedom in all directions except that in the axial direction at one column end. The non-linearity of aluminium alloys was considered in the FE simulation by using the plasticity model in ABAQUS [16].

The ultimate compression capacities of 28 columns in plain and lipped channel sections obtained from FE and tests were compared to validate the model [15]. Results showed that the differences between the FE model prediction and the test results were small. The mean value of the ratios of the numerical over experimental results $\left(P_{F E} / P_{E x p}\right)$ was 0.95 , and the corresponding coefficient of variation (COV) was 0.101 . The FE models accurately predicted the failure modes of the channel section columns (see Fig. 4), and the load-deformation curves were well predicted as well, as shown in Fig. 5. Therefore, the FE model is valid and can be used for the following parametric study. 


\subsection{Parametric study}

The effective lengths considered in parametric study include 500, 1200, 2000, 2700, and $3500 \mathrm{~mm}$. The cross-section considered in parametric study covered the width of flat elements ranging from $60 \mathrm{~mm}$ to $200 \mathrm{~mm}$ and the thickness of $2 \mathrm{~mm}$ and $3 \mathrm{~mm}$. The plate width-to-thickness ratio $\mathrm{b} / \mathrm{t}$ varied from 20 to 120 , and the slenderness ratio varied from 50 to 200 . The parametric study used the material model of high-strength aluminium alloys and normal-strength aluminium alloys using the experimentally determined properties, as given in Tables 1 and 2. The initial geometric imperfection was taken as the mean value measured from specimens where the local geometric imperfection was $16 \%$ of the thickness of the component, and the global geometric imperfection was taken as $1 / 2000$ of the component length.

\section{Design Method Comparisons}

The design strengths of aluminium alloy columns were predicted using the international design standards, and then compared with experimental and simulation results. These standards include Aluminium Design Manual (AA) [5], Australia/New Zealand Standards (AS/NZS) [6], Eurocode 9 (EC9) [7], and Chinese Code for Design of Aluminium Structures (CN) [8]. In addition, two design approaches - DSM [5, 10] and CSM [13, 14] were also considered. All dimensions and material properties used in the predictions were obtained from measurement and material property tests. In all calculations, safety factors were set to unity.

\subsection{Aluminium Design Manual}

The column strength prediction of the AA specification $\left(P_{A A-1}\right)$ uses the lowest of the available strengths for the limit states of member buckling $\left(P_{n c 1}\right)$, local buckling $\left(P_{n c 2}\right)$, and the interaction between member buckling and local buckling $\left(P_{n c 3}\right)$. This is determined as shown in Eq. (1):

$$
P_{A A-1}=\min \left(P_{n c 1}, P_{n c 2}, P_{n c 3}\right)
$$

Member buckling strength $\left(P_{n c l}\right)$ is given by (Chapter E.2):

$$
P_{n c 1}=f_{c} A_{g}
$$

For the yielding condition $\left(\lambda \leq \lambda_{1}\right): f_{c}=f_{y}$

For the inelastic buckling condition $\left(\lambda_{1}<\lambda<\lambda_{2}\right): f_{c}=\left(B_{c}-D_{c} \lambda\right)\left(0.85+0.15 \frac{C_{c}-\lambda}{C_{c}-\lambda_{1}}\right)$

For the elastic buckling condition $\left(\lambda \geq \lambda_{2}\right): f_{c}=0.85 \pi^{2} E / \lambda^{2}$

The local buckling strength $\left(P_{n c 2}\right)$ is as follows (Chapter E.3.1):

$$
P_{n c 2}=\sum_{i=1}^{n} f_{c i} A_{i}+f_{y}\left(A_{g}-\sum_{i=1}^{n} A_{i}\right)
$$


The strength of interaction between member buckling and local buckling $\left(P_{n c 3}\right)$ is calculated from (Chapter E.4):

$$
P_{n c 3}=\left[\frac{0.85 \pi^{2} E}{\lambda^{2}}\right]^{2} f_{e}^{2 / 3} A_{g}
$$

where:

$A_{g}=$ gross cross-sectional area

$A_{i}=$ area of element $i$

$B_{c}, C_{c}, D_{c}=$ buckling constant intercept for flexural compression in flat elements as given in Table B 4.2 [5]

$f_{c}=$ stress corresponding to the uniform compressive strength

$f_{c i}=$ local buckling stress of element $i$

$f_{e}=$ elastic buckling stress can be obtained from Table B.5.1 [5]

$\lambda=$ the greatest column slenderness

$\lambda_{1}=\left(B_{c}-f_{c y}\right) / D_{c}$, slenderness at the intersection of equations for yielding (Eq. 3$)$ and inelastic buckling (Eq. 4)

$\lambda_{2}=C_{c}$, slenderness at the intersection of equations for inelastic buckling and elastic buckling

\subsection{Aluminium Design Manual (Direct Strength Method)}

The direct strength method (DSM) for aluminium alloy column design is included in the Chapter E.3.2 of the latest version of American Aluminium Design Manual [5]. However, it can only predict cross-section resistance considering local buckling. Therefore, in this study, the design strength of DSM in AA $\left(P_{A A-2}\right)$ is only calculated and compared with experimental results of short columns. The DSM design strength is determined as follows:

$$
P_{A A-2}=f_{c} A
$$

For the yielding condition $\left(\lambda_{e q} \leq \lambda_{3}\right): f_{c}=f_{y}$

For the inelastic buckling condition $\left(\lambda_{3}<\lambda_{e q}<\lambda_{4}\right): f_{c}=B_{p}-D_{p} \lambda_{e q}$

For the elastic buckling condition $\left(\lambda \geq \lambda_{4}\right): f_{c}=\left(2.27 \sqrt{B_{p} E}\right) / \lambda_{e q}$

where $\lambda_{3}$ is the slenderness at the intersection of the equations for yielding and inelastic buckling given by: $\lambda_{3}=\left(B_{p}-f_{c}\right) / D_{p}, \lambda_{4}$ is the slenderness at the intersection of the equations for inelastic buckling and elastic buckling given by: $\lambda_{4}=0.35 B_{p} / D_{p}, \lambda_{e q}$ is the equivalent slenderness for alternate determination of compressive strength for flexural or axial compression given by: $\lambda_{e q}=\pi \sqrt{E / f_{e}}$.

\subsection{Australian/New Zealand Standards}

The design rules in the AS/NZS standards [6] are essentially the same as those in the AA code [5] 
as shown previously in Section 4.1 .

\subsection{Eurocode 9}

According to the EC9 [7], under the axial compression loading, structure members could fail by flexural, torsional or flexural torsional and local squashing. Effective cross-section method is used to calculate the compression section capacity. The design rule strength in EC9 $\left(P_{E C 9}\right)$ is determined as follows:

$$
P_{E C 9}=\min \left(P_{c, R d}, P_{b, R d}\right)
$$

The design resistance for uniform compression $\left(P_{c, R d}\right)$ :

$$
P_{c, R d}=A_{e} f_{y}
$$

where $A_{e}$ is the effective area of cross section that can be obtained by employing a local buckling reduction factor $\rho_{c}$ to factor down the component thickness according to:

$$
\rho_{c}=\left\{\begin{array}{cc}
1.0 & \beta \leq \beta_{3} \\
\frac{9}{(\beta / \varepsilon)}-\frac{20}{(\beta / \varepsilon)^{2}} & \beta>\beta_{3}
\end{array}\right.
$$

where $_{\beta}={ }_{b / t}$ is the width-to-thickness ratio, $\varepsilon=\sqrt{250 / f_{y}}$ is the slenderness coefficient, and $\beta_{3}=$ $5 \varepsilon$ is the slenderness limit of Class 3 sections.

The design buckling resistance of a compression member $\left(P_{b, R d}\right)$ without welding is given by:

$$
P_{b, R d}=\chi A_{e} f_{y}
$$

where $\chi$ is the reduction factor related to the relevant buckling mode given by:

$$
\begin{aligned}
& \chi=\frac{1}{\phi+\sqrt{\phi^{2}-\bar{\lambda}^{2}}} \leq 1.0 \\
& \phi=0.5\left(1+\alpha\left(\bar{\lambda}-\bar{\lambda}_{0}\right)+\bar{\lambda}^{2}\right)
\end{aligned}
$$

For the flexural buckling condition:

$$
\bar{\lambda}=(k L / i \pi) \sqrt{A_{e} f_{y} / A E}
$$

For the torsional or torsional-flexural buckling condition:

$$
\bar{\lambda}=\sqrt{A_{e} f_{y} / P_{c r}}
$$

where

$b=$ flat width of flange

$i=$ gyration's radius about its relevant axis

$k=0.85$, buckling length factor for members

$P_{c r}=$ elastic critical load for torsional buckling, allowing for interaction with flexural buckling if necessary 
$\alpha=$ imperfection factor can be obtained from Table 6.6 [7] for flexural and Table 6.7 [7] for torsional or torsional-flexural buckling.

$\bar{\lambda}=$ relative slenderness

$\bar{\lambda}_{0}=$ limit of the horizontal plateau in the buckling curves, which can be gained from Table 6.6 of EC9 [7] for flexural and Table 6.7 of EC9 [7] for torsional or torsional-flexural buckling.

\subsection{Chinese Code for Design of Aluminium Structures}

The design strength from the Chinese Code [8] $\left(P_{C N}\right)$ are based on the effective thickness method that considers the local buckling and asymmetry of the cross section.

$$
P_{C N}=\bar{\varphi} A f_{y}
$$

where $\bar{\varphi}$ is the stability coefficient for non-welded compression members, given by $\bar{\varphi}=\eta_{e} \eta_{a s} \varphi$, where $\eta_{e}$ is the section correction coefficient considering local buckling, given by $\eta_{e}=A_{e} / A$, $\eta_{a s}$ is the sectional asymmetric coefficient, and $\varphi$ is the stability coefficient for the column.

For normal strength aluminium alloys:

$$
\eta_{a s}=1-2.4 \psi^{2} \frac{\bar{\lambda}^{2}}{\left(1+\bar{\lambda}^{2}\right)(1+\bar{\lambda})^{2}}
$$

For high strength aluminium alloys:

$$
\eta_{a s}=1-3.2 \psi^{2} \frac{\bar{\lambda}^{2}}{\left(1+\bar{\lambda}^{2}\right)(1+\bar{\lambda})^{2}}
$$

where $\psi=\left(y_{\max }-y_{\min }\right) / H, y_{\min }$ and $y_{\min }$ are the distance from the outer edge of the section to the centroid, and the slenderness is $\bar{\lambda}=\frac{\lambda}{\pi} \sqrt{\frac{\eta_{e} f_{y}}{E}}$.

The section correction coefficient is calculated by Eq. (22):

$$
\varphi=\left(\frac{1}{2 \bar{\lambda}^{2}}\right)\left\{\left(1+\eta+\bar{\lambda}^{2}\right)-\left[\left(1+\eta+\bar{\lambda}^{2}\right)^{2}-4 \bar{\lambda}^{2}\right]^{1 / 2}\right\} \leq 1.0
$$

where the slenderness $\bar{\lambda}=\frac{\lambda}{\pi} \sqrt{\frac{f_{y}}{E}}$ and $\eta$ is the coefficient considering initial eccentricity and initial bending as given by:

For the normal strength aluminium alloy:

$$
\eta=0.2(\bar{\lambda}-0.15)
$$

For the high strength aluminium alloy: 


\subsection{North American Standard (Direct Strength Method)}

The direct strength method (DSM) approach for steel structural members has been included in the North America specification for cold-formed steel structures (NAS) [10] ( $\left.P_{\text {NAS }}\right)$. It covers both short column and long column design with considering the influences of the global buckling, the coupling effect of the global buckling and local buckling, and the coupling effect of the distortional buckling and component yielding. The DSM design strength is determined as follows:

$$
P_{N A S}=\min \left(P_{n e}, P_{n l}, P_{n d}\right)
$$

Flexural, torsional, or flexural-torsional buckling load $\left(P_{\mathrm{ne}}\right)$ is given from:

$$
P_{n e}=\left\{\begin{array}{cc}
\left(0.685^{\lambda_{c}^{2}}\right) P_{y} & \lambda_{c} \leq 1.5 \\
\left(0.877 / \lambda_{c}^{2}\right) P_{y} & \lambda_{c}>1.5
\end{array}\right.
$$

Local buckling load $\left(P_{\mathrm{nl}}\right)$ is determined by:

$$
P_{n l}=\left\{\begin{array}{cc}
P_{n e} & \lambda_{l} \leq 0.776 \\
P_{n l}=\left[1-0.15\left(\frac{P_{c r l}}{P_{n e}}\right)^{0.4}\right]\left(\frac{P_{c r l}}{P_{n e}}\right)^{0.4} P_{n e} & \lambda_{l}>0.776
\end{array}\right.
$$

Distortional buckling load $\left(P_{\mathrm{nd}}\right)$ is calculated according to:

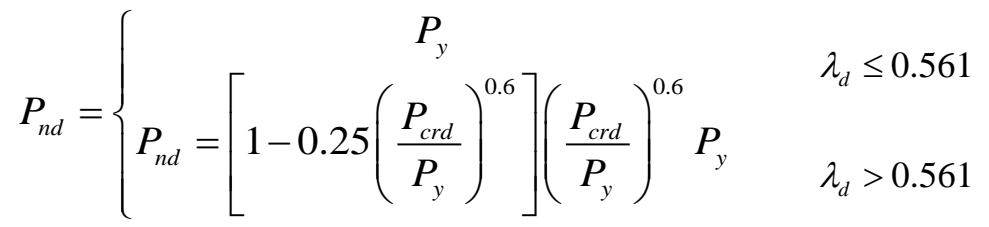

where

$P_{y}=f_{y} A$

$P_{c r d}=$ critical value of elastic distortional column buckling load

$P_{c r e}=$ minimal value of the critical elastic column buckling load for flexural, torsional, or torsional-flexural buckling

$P_{c r l}=$ critical value of elastic local column buckling load

$\lambda_{c}=\sqrt{P_{y} / P_{c r e}}$, cross-section slenderness for the flexural, torsional, or flexural-torsional buckling

$\lambda_{d}=\sqrt{P_{y} / P_{c r d}}$, cross-section slenderness for the distortional buckling

$\lambda_{l}=\sqrt{P_{n e} / P_{c r l}}$, cross-section slenderness for the local buckling

\subsection{Continuous strength method}

As a deformation-based design method, the CSM employs a continuous base curve representing 
the cross-section deformation capacity and slenderness. It also takes into account the impact of strain hardening by using a bi-linear material model in the calculation of section resistances [14]. However, the current CSM approach can only predict the aluminium alloy cross-section resistance, it has not covered the long column compression design. Thus, in this study, the CSM is only used to predict the compression resistance of columns failed by local buckling. The CSM design procedure is shown below:

$$
P_{C S M}=\left\{\begin{array}{cc}
A f_{c s m} & \overline{\lambda_{p}} \leq 0.68 \\
\frac{\varepsilon_{c s m}}{\varepsilon_{y}} A f_{y} & \overline{\lambda_{p}}>0.68
\end{array}\right.
$$

where $\bar{\lambda}_{p}$ is the cross-section slenderness given by $\bar{\lambda}_{p}=\sqrt{f_{y} / \sigma_{c r}}$ and $\sigma_{c r}$ is the elastic buckling stress, which can be numerically obtained using programmes such as CUFSM [17].

The CSM limiting stress is determined from:

$$
f_{c s m}=f_{y}+E_{s h}\left(\varepsilon_{c s m}-\varepsilon_{y}\right)
$$

The strain hardening modulus is calculated according to:

$$
E_{s h}=\left(f_{u}-f_{y}\right) /\left(0.5 \varepsilon_{u}-\varepsilon_{y}\right)
$$

The deformation capacity of cross sections is as follows:

$$
\frac{\varepsilon_{c s m}}{\varepsilon_{y}}=\left\{\begin{array}{cc}
\frac{0.25}{\bar{\lambda}_{p}^{3.6}}<\min \left(15, \frac{0.5 \varepsilon_{u}}{\varepsilon_{y}}\right) & \overline{\lambda_{p}} \leq 0.68 \\
\frac{1}{\bar{\lambda}_{p}^{1.05}}\left(1-\frac{0.222}{\bar{\lambda}_{p}^{1.05}}\right) & \overline{\lambda_{p}}>0.68
\end{array}\right.
$$

where $\varepsilon_{u}=0.13\left(1-f_{y} / f_{u}\right)+0.059$, which is the strain at ultimate tensile stress; $\varepsilon_{y}=f_{y} / E$, which is the yield strain.

\subsection{Result comparisons}

The nominal design strengths calculated by the seven design methods in Sections $4.1-4.7$ were used in comparison with the ultimate strengths $\left(P_{u}\right)$ experimentally and numerically obtained in this study. The testing specimen's material properties and geometry dimensions were used as inputs in the six design methods to determine the design strengths. Tables 4 and 5 present the comparisons of test strengths with the calculated design strengths. The comparison of the results from the experiments and simulations with the predictions from the six design methods are shown in Fig. 6 and summarized in Tables 6-7.

For the plain channel section columns, it is shown that the Chinese standard (CN) is highly conservative (the mean value of $P_{u} / P_{C N}=1.63$ and the COV $=0.196$ ). The prediction of Eurocode 9 is less conservative but shares a similar scatter level as the Chinese standard the mean value of $P_{u} / P_{E C 9}=1.32$ and the $\mathrm{COV}=0.188$ ). The American Design Manual and the Australia/New Zealand Standards are identical and have a less conservative value than EC9 (mean value equals to 1.20 with COV being 0.145). The existing design specifications generally provide conservative design strengths. The predictions calculated by the DSM specified in AA are rather conservative 
(mean value of $P_{u} / P_{\mathrm{AA}-2}=1.42$ ), but the DSM specified in NAS are much more accurate (mean value of $\left.P_{u} / P_{N A S}=1.01\right)$. The load ratios for the CSM $\left(P_{u} / P_{C S M}\right)$ have mean values of 1.01 and COV of 0.072 , which is the most accurate and consistent, though it is limited as it only predicts the compression capacity of short columns.

For the lipped channel section columns with data given in Table 6, the prediction accuracy and scatter level of the AA $\left(P_{u} / P_{A A-1}\right)$, AS/NZS $\left(P_{u} / P_{A S / N Z S}\right)$ and $\mathrm{CN}\left(P_{u} / P_{C N}\right)$ standards are similar. The design strength calculated by EC9 for lipped channel section columns is slightly less conservative (the mean value of $P_{u} / P_{E C 9}=1.41$ and the $\mathrm{COV}=0.206$ ), and had a little less scatter than the AA, $\mathrm{AS} / \mathrm{NZS}$, and $\mathrm{CN}$ results. The experimental and numerical loads over predictions for the DSM specified in $\mathrm{AA}\left(P_{u} / P_{\mathrm{AA}-2}\right)$ and $\operatorname{NAS}\left(P_{u} / P_{N A S}\right)$ have mean values of 1.30 and 1.09 , and the corresponding COV are 0.222 and 0.175 . Similar to plain channel section, the DSM approach codified in NAS seems to be more accurate for the aluminium alloy column design. The CSM approach provide more accurate assessments than other design methods with less scatter in their results (mean value of $P_{u} / P_{C S M}=1.10$ and $\mathrm{COV}=0.129$ ).

\section{Reliability Analysis}

The reliability index is an important parameter for the assessment of the reliability level of a design method. The structure design method is reliable if the reliability index $(\beta)$ is not less than 2.50 . The design load combinations used in the reliability analysis are specified as $1.2 \mathrm{D}+1.6 \mathrm{~L}$ for AA, $1.25 \mathrm{D}+1.5 \mathrm{~L}$ for $\mathrm{AS} / \mathrm{NZS}, 1.35 \mathrm{D}+1.5 \mathrm{~L}$ for $\mathrm{EC}, 1.2 \mathrm{D}+1.4 \mathrm{~L}$ for $\mathrm{CN}$, where $D$ is the dead load and $L$ represents the live load. The resistance factors of the AA, AS/NZS, EC9, and CN are specified as $0.85,0.85,0.91$, and 0.83 , respectively. Here, for the DSM and CSM approaches, the load combination was taken as $1.2 \mathrm{D}+1.6 \mathrm{~L}$, and the resistance factor was 0.85 , using AA as a basis.

The determined reliability indexes $\beta$ of the different design rules are shown in Tables 6 and 7 for plain and lipped channel sections, respectively. For the plain channel section columns, the reliability indexes $\beta$ of the AA, AS/NZS, EC9, CN, DSM in AA code and CSM were greater than 2.50 , which are deemed to be reliable for aluminium alloy columns of plain sections. However, the reliability index ${ }_{\beta}$ of the DSM in NAS was found to be 2.18 , lower than the target value of 2.50 . Thus, the DSM approach in NAS failed to pass the reliability analysis; the main reason is related to the scatter of predicted results. For the lipped channel section columns, the reliability indexes ${ }_{\beta}$ of the four specifications and the CSM approach were greater than the target value of 2.50 . The reliability index $_{\beta}$ of the DSM approaches codified in both AA and NAS were found to be 2.41 and 2.20, respectively. Again, the DSM is deemed to be unsafe for the design of lipped channel section columns. Modifications to the DSM approach are suggested to achieve reliable predictions in the future.

\section{Conclusions}

The aluminium alloy columns with plain and lipped channel sections were experimentally and numerically studied. In the experimental program, a total of 28 aluminium alloy columns with plain and lipped channel sections were tested. A FE model was developed and verified by experimental data. Upon validation, the FE model was applied to generate 100 numerical results. For short columns, the failure mode was local buckling. As the length of specimens increases, the failure 
modes changed. The medium columns generally failed by local and flexural buckling for plain channels, and local and flexural-torsional buckling for lipped channels, while the long columns failed by a combination of local buckling, flexural buckling and flexural-torsional buckling for plain channels, but flexural-torsional buckling only for lipped channels in this study. Afterwards, the results of the experiments and simulations were compared to those predicted by design methods. It was shown that the design strengths obtained by the international design specifications are rather conservative and scattered. Generally, the DSM approaches codified in aluminium alloy and cold-formed steel codes had more accurate strength predictions. The CSM yielded the most accurate and consistent predictions for the stub columns that failed by local buckling. Reliability analysis showed that the design methods in specifications and the CSM approach are safe and reliable for aluminium alloy channel columns. The DSM approach in AA was shown to be unreliable for lipped channel section columns, whereas the DSM approaches in NAS was found to fail the reliability analysis for both plain and lipped channel section columns.

\section{Acknowledgments}

We would like to thank the funding support from The University of Hong Kong in the seed funding program for basic research and from the Chinese National Natural Science Foundation (51508336, 51538007, 51478269), the Key Project of Department of Education of Guangdong Province (No.2014KZDXM051) and the Shenzhen science and technology project (JCYJ20170818094820689). The support provided by the technician in the Structural Engineering Laboratory at The University of Hong Kong for the test program is also acknowledged.

\section{Notations}

$\begin{array}{ll}A & \text { gross cross-sectional area } \\ A_{e} & \text { effective sectional area } \\ A_{i} & \text { area of element } i \\ b & \text { flat width } \\ B & \text { section width } \\ B_{c} & \text { buckling constant intercept for member buckling } \\ B_{p} & \text { buckling constant intercept for uniform compression in flat elements } \\ C_{c} & \text { buckling constant intersection for member buckling } \\ D_{c} & \text { buckling constant slope for member buckling } \\ D_{p} & \text { buckling constant slope for uniform compression in flat elements } \\ E & \text { Young's modulus } \\ E_{s h} & \text { strain hardening modules } \\ f_{c s m} & \text { CSM limiting stress } \\ f_{u} & \text { material ultimate stress } \\ f_{y} & \text { material yield strength (i.e., the static } 0.2 \% \text { proof stress) } \\ f_{c} & \text { stress corresponding to the uniform compressive strength } \\ f_{c i} & \text { local buckling stress of element } i \\ f_{e} & \text { elastic buckling stress }\end{array}$




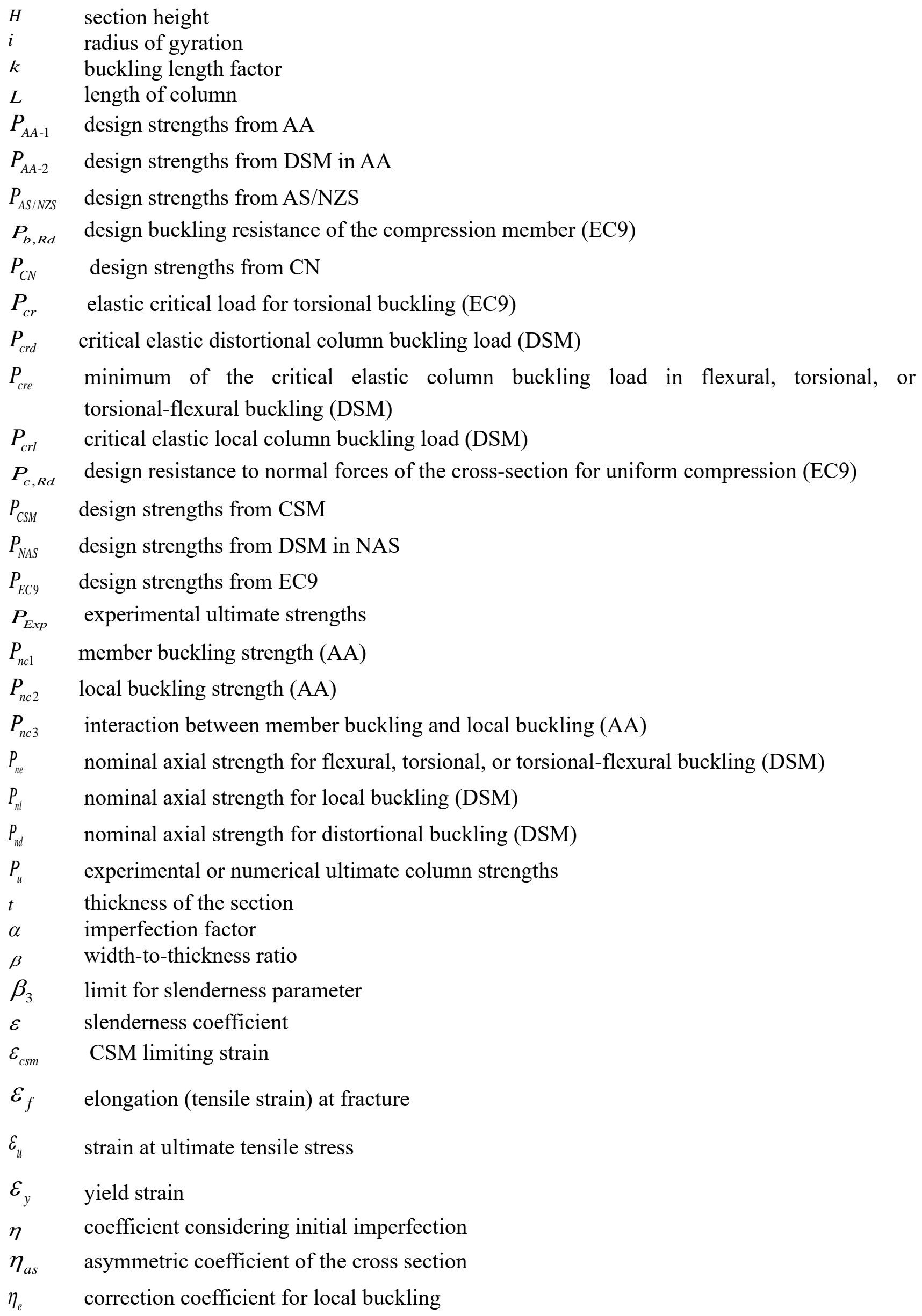


$\lambda \quad$ column slenderness

$\bar{\lambda}_{0} \quad$ slenderness coefficient considering different aluminium alloys

$\lambda_{1} \quad$ slenderness at the inter section of equations for yielding and inelastic buckling

$\lambda_{2}$ slenderness at the inter section of equations for inelastic buckling and elastic buckling

$\lambda_{3}$ slenderness at the intersection of the equations for yielding and inelastic buckling

$\lambda_{4}$ slenderness at the intersection of the equations for inelastic buckling and elastic buckling

$\lambda_{c} \quad$ cross-section slenderness for the flexural, torsional, or torsional-flexural buckling

$\lambda_{d} \quad$ cross-section slenderness for the distortional buckling

$\lambda_{e q} \quad$ equivalent slenderness for alternate determination of compressive strength for flexural or axial compression

$\lambda_{l} \quad$ cross-section slenderness for the local buckling

$\bar{\lambda}_{p} \quad$ cross-section slenderness

$\rho_{c} \quad$ reduction factor for local buckling

$\sigma_{c r} \quad$ elastic buckling stress

$\varphi \quad$ stability coefficient

$\bar{\varphi} \quad$ stability coefficient for non-welded compressive members

$\chi \quad$ local buckling coefficient

\section{References}

[1] Zhu, J.H., Young, B., Tests and Design of Aluminum Alloy Compression Members, J. Struct. Eng. ASCE 132 (7) (2006) 1096-1107.

[2] Zhu, J.H., Young, B., Numerical investigation and design of aluminum alloy circular hollow section columns, Thin-Walled Struct.46 (12) (2008) 1437-1449.

[3] Huynh, L.A.T., Pham, C.H. and Rasmussen, K. J. R., Numerical Simulations of Cold-Rolled Aluminium Alloy 5052 Channel Sections in Stub Column Tests, Congrès International de Géotechnique - Ouvrages - Structures Springer, Singapore (2017) 202-212.

[4] Mazzolani, F. M., V. Piluso, G. Rizzano, Local Buckling of Aluminum Alloy Angles under Uniform Compression, J. Struct. Eng. 137 (2) (2011) 173-184.

[5] Aluminium Association, Aluminium Design Manual, The Aluminium Association, Washington, DC, 2015.

[6] AS/NZS, Aluminium Structures-Part 1: Limit State Design, Australian/New Zealand Standard AS/NZS1664.1:1997. Sydney, Australia: Standards Australia,1997

[7] European Committee for Standardization (EC9), EUROCODE 9: Design of Aluminium Structures-Part 1-1: General Rules and Rules for Buildings, BS EN 1999-1-1:2007, CEN, 2007.

[8] CN. Code for design of aluminium structures. Ministry of Construction of the People's Republic of China. GB50429-2007.

[9] Schafer, B W, Peköz, T., Direct Strength Prediction of Cold-Formed Steel Members using Numerical Elastic Buckling Solutions, Thin-walled Struct. (1998). 
[10] AISI. North American Specification for the Design of Cold-formed Steel Structural Members, American Iron and Steel Institute, AISI S100-12, Washington, DC, 2012.

[11] Zhu, J.H., Young, B., Aluminum alloy tubular columns-Part I: Finite element modeling and test verification, Thin-Walled Struct.44 (9) (2006) 961-968.

[12] Zhu, J.H., Young, B., Aluminum alloy tubular columns-Part II: Parametric study and design using direct strength method, Thin-Walled Struct. 44 (9) (2006) 969-985.

[13] Su, M.N., Young, B., Gardner, L., Testing and Design of Aluminum Alloy Cross Sections in Compression, J. Struct. Eng. 140 (9) (2014) 04014047.

[14] Su, M.N., Young, B., Gardner, L., The continuous strength method for the design of aluminium alloy structural elements, J. Struct. Eng. ASCE 122 (2016) 338-348.

[15] Zhu J, Wang P, Liu T, Numerical simulation and design of aluminum compression members with plain and lipped channel sections. Jianzhu Jiegou Xuebao, Journal of Building Structures, 31 (2010) 163-168.

[16] ABAQUS Analysis User's Manual, version6.12, ABAQUS Inc.,2010.

[17] Seif, M., Schafer, B. W., Local buckling of structural steel shapes. Journal of Constructional Steel Research 66 (10) (2010) 1232-1247. 


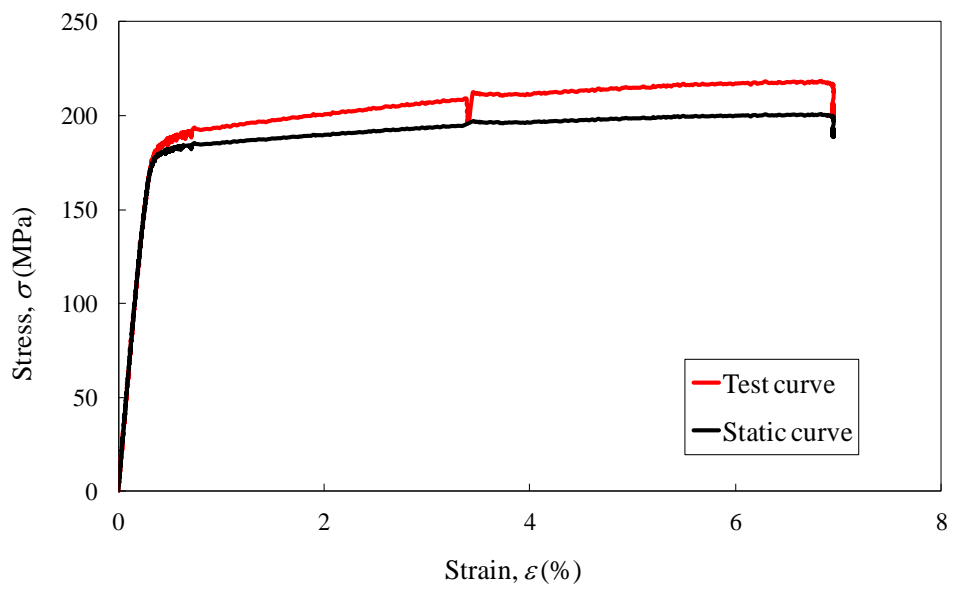

(a) Aluminium alloy T5

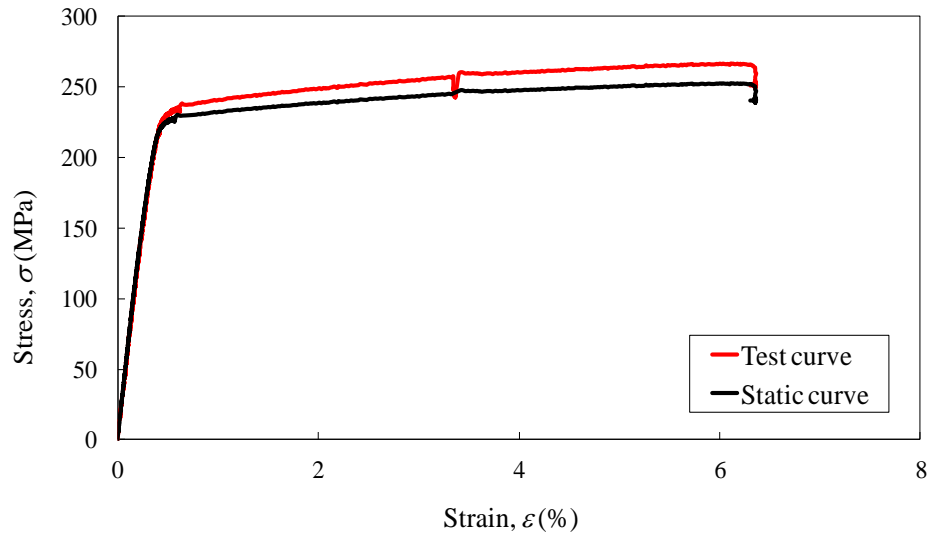

(b) Aluminium alloy T6

Fig. 1. Typical stress-strain curves for aluminium alloys 


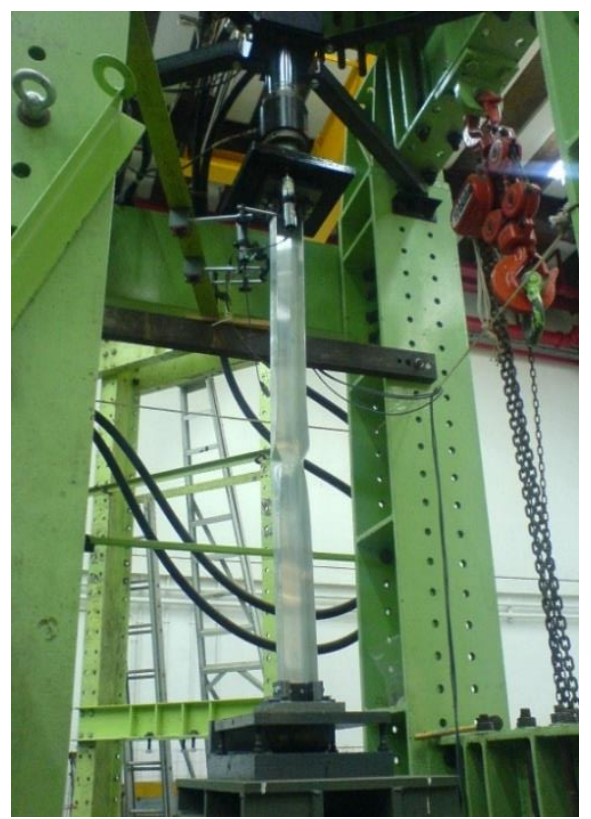

(a) Plain channel section

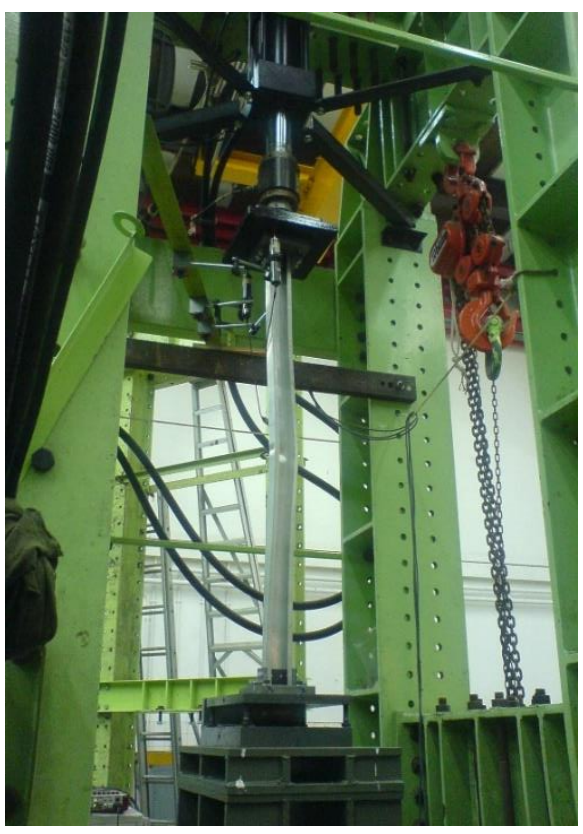

(b) Lipped channel section

Fig. 2. Test configuration and failure modes for long columns 


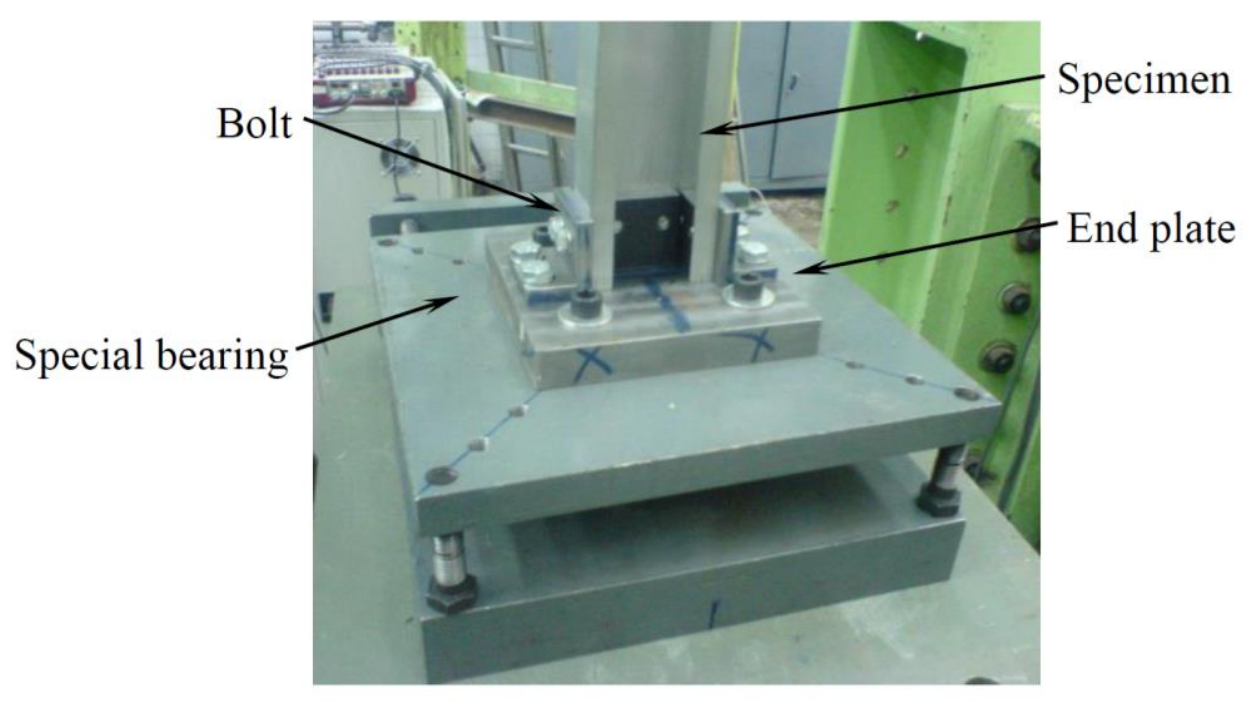

Fig. 3. Fixed-ended boundary condition 

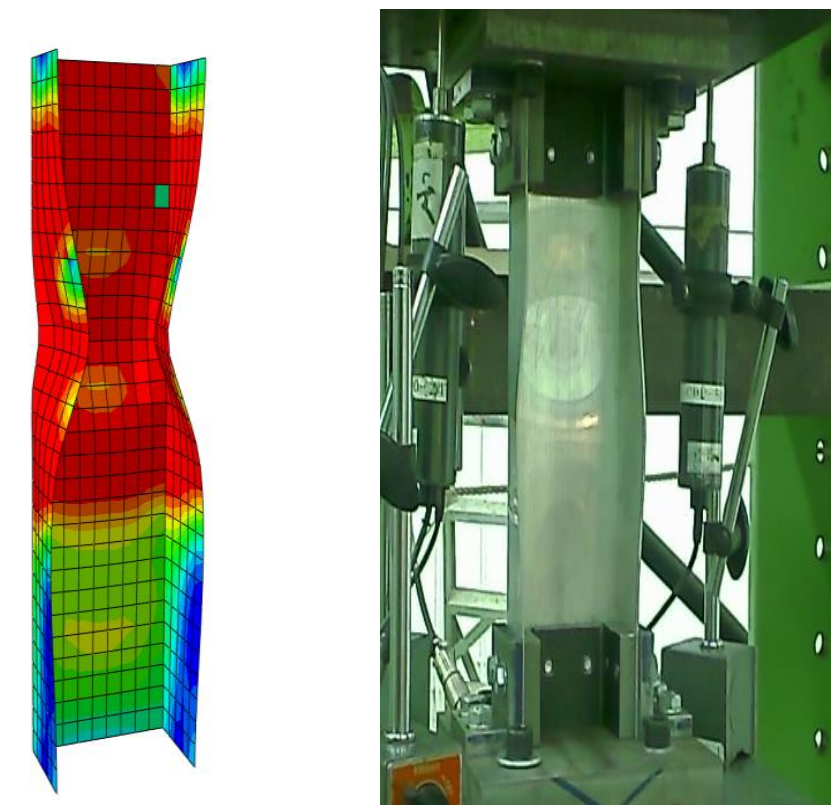

(a) Specimen P-T5-L300 (failure mode: local buckling)

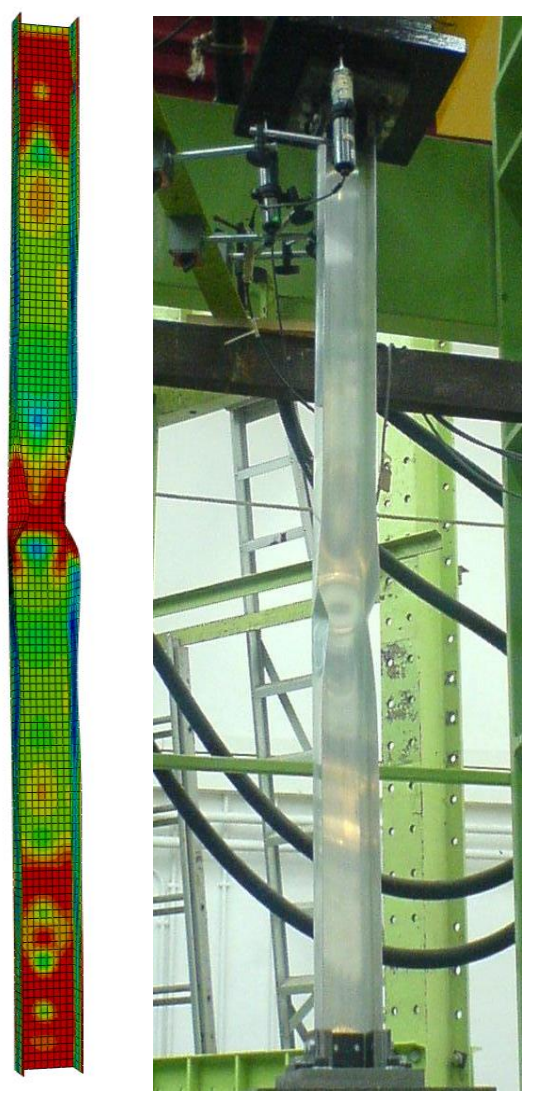

(b) Specimen P-T6-L1350 (failure mode: local and flexural buckling) 


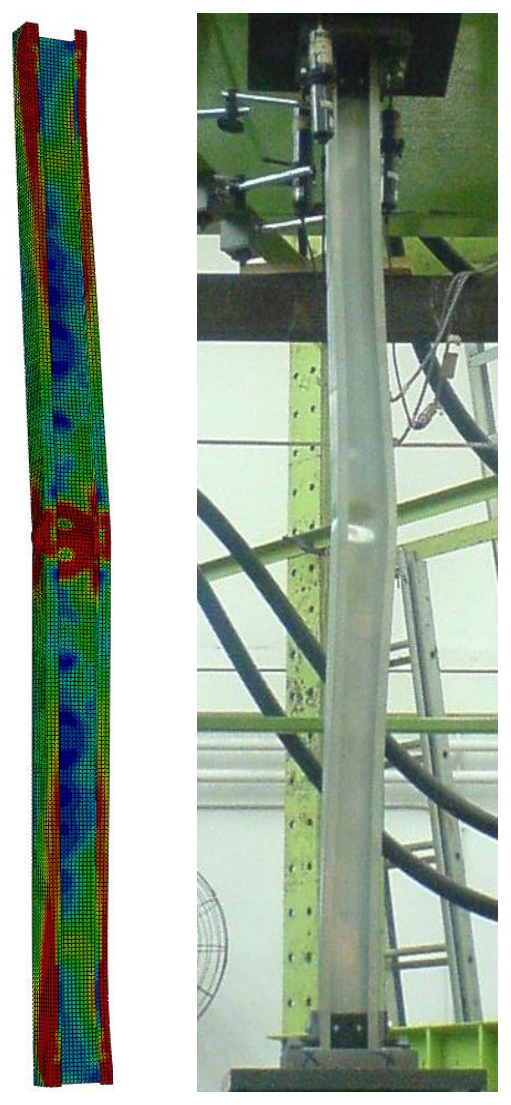

(c) Specimen L-T5-L1350 (failure mode: local and flexural-torsional buckling)

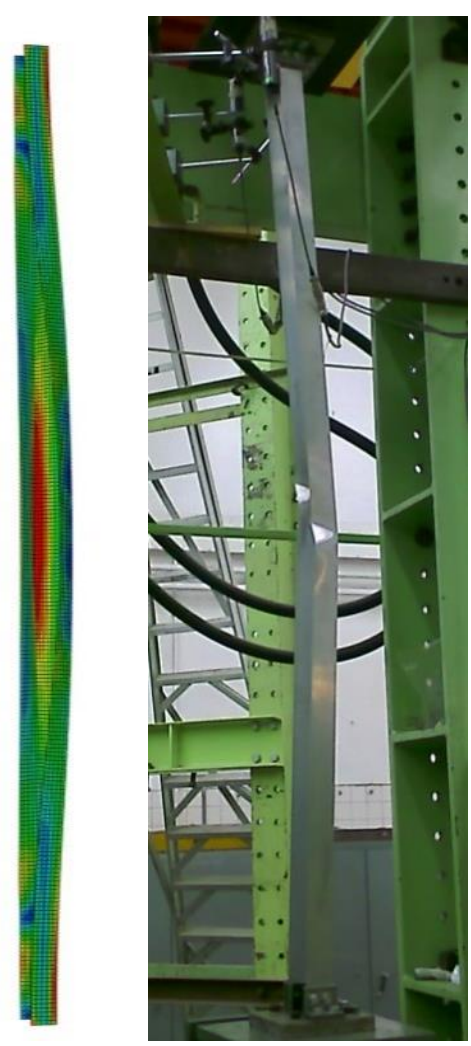

(d) Specimen P-T6-L2450 (failure mode: local, flexural and flexural-torsional buckling)

Fig. 4. Deformed shapes of specimens 


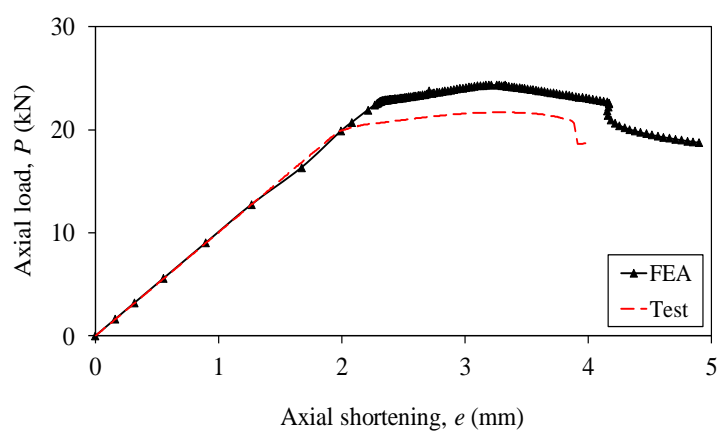

(a) Specimen P-T5-L2450

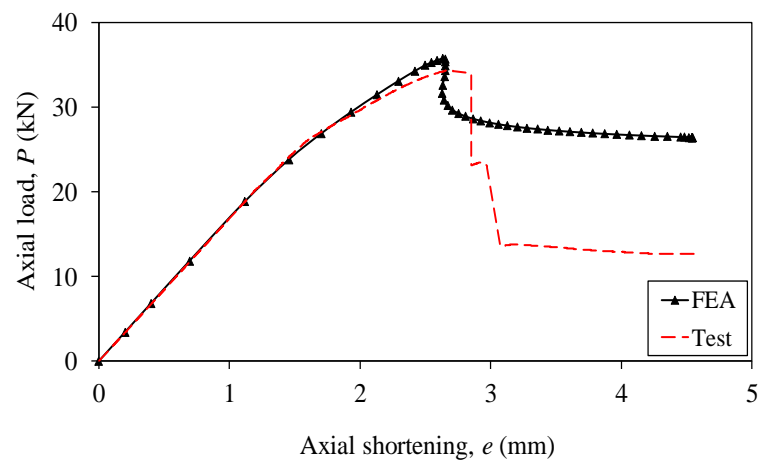

(b) Specimen P-T6-L1350

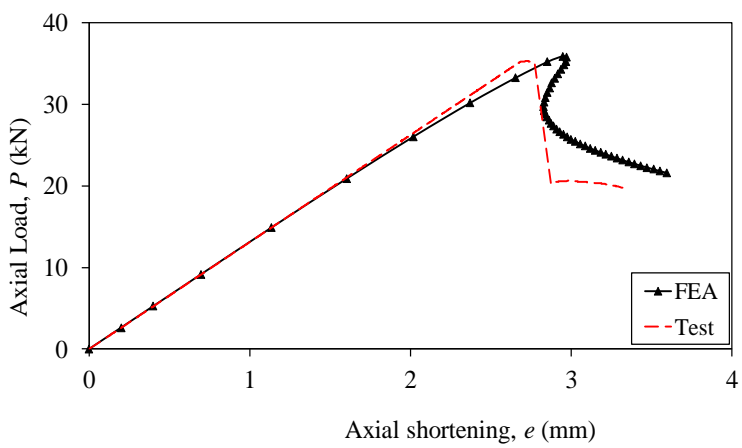

(c) Specimen L-T5-L1350

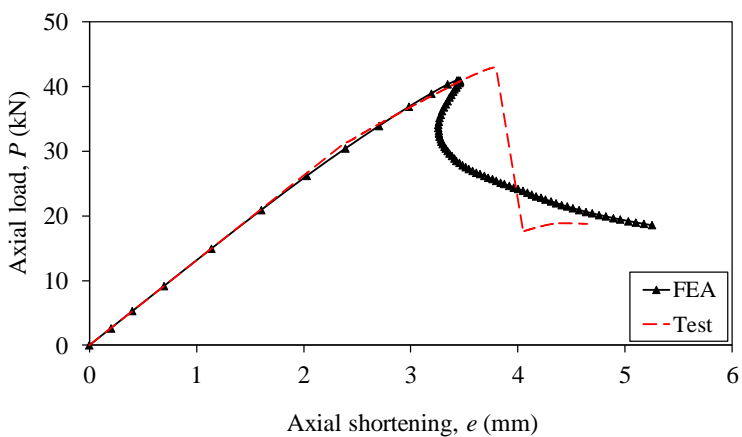

(d) Specimen L-T6-L1350

Fig. 5. Comparison of the FEA and test curves 


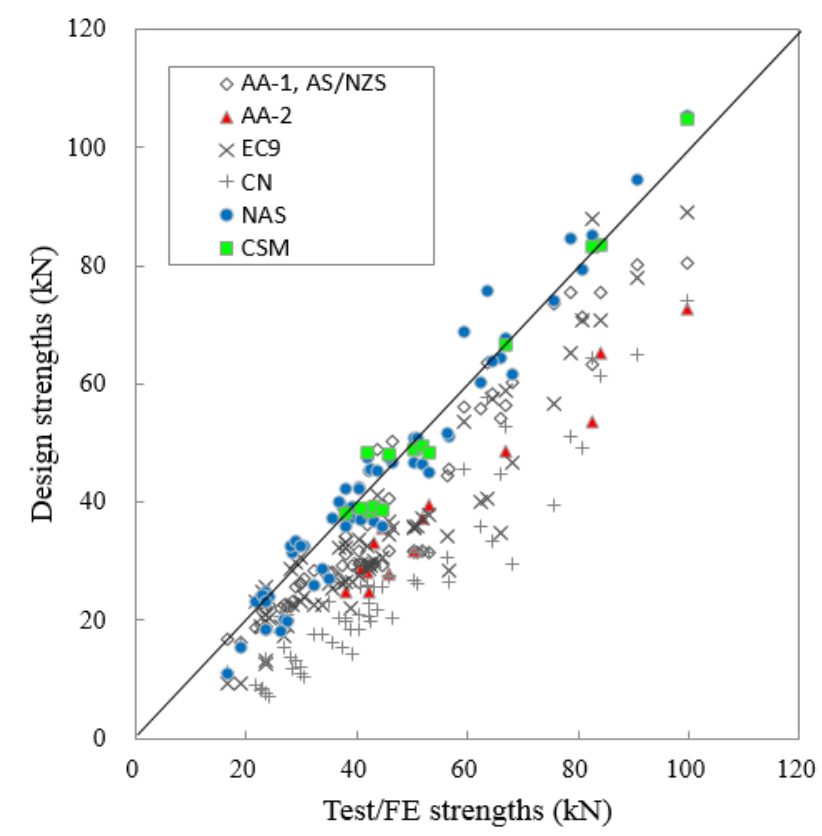

(a) Plain channel sections

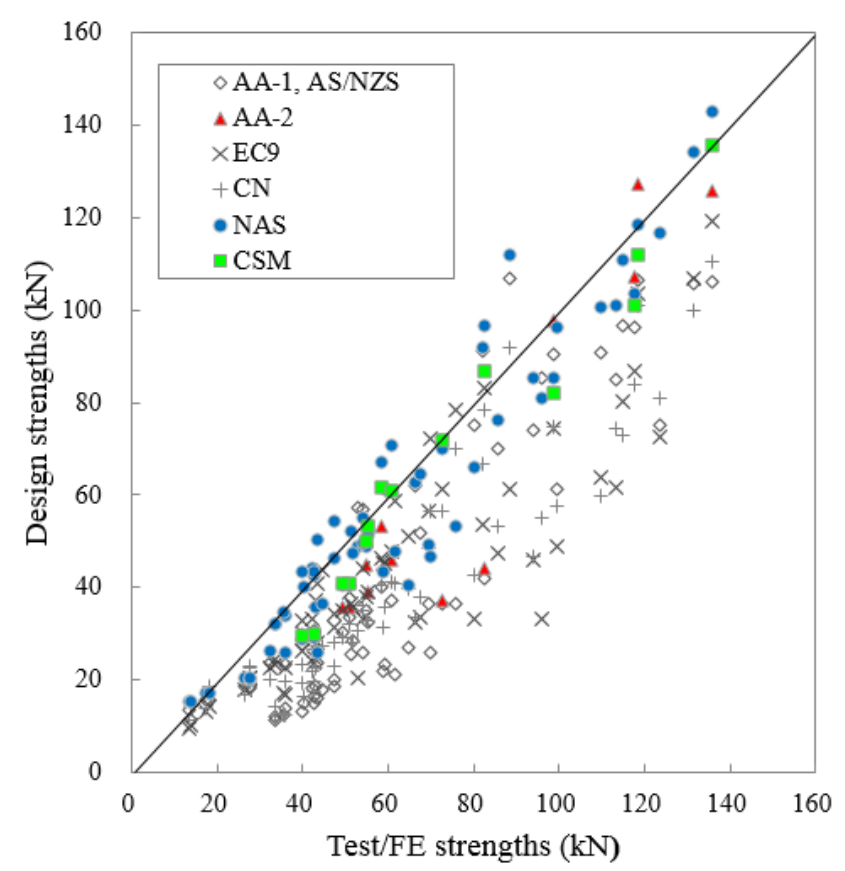

(b) Lipped channel sections

Fig. 6. Comparison of test and finite element ultimate strengths with design predictions 
Table 1. The fabricated specimens and their material properties for plain channel sections [15]

\begin{tabular}{lcccccccc}
\hline Specimens & $H$ & $B$ & $t$ & $L$ & $E$ & $f_{y}$ & $f_{u}$ & $\varepsilon_{f}$ \\
& $(\mathrm{~mm})$ & $(\mathrm{mm})$ & $(\mathrm{mm})$ & $(\mathrm{mm})$ & $(\mathrm{GPa})$ & $(\mathrm{MPa})$ & $(\mathrm{MPa})$ & $(\%)$ \\
\hline P-T5-L300 & 86.8 & 50.0 & 1.93 & 299.9 & 67 & 181 & 201 & 6.9 \\
P-T5-L800 & 86.8 & 49.9 & 1.93 & 800.1 & 67 & 181 & 201 & 6.9 \\
P-T5-L1350 & 86.8 & 49.9 & 1.92 & 1350.1 & 67 & 181 & 201 & 6.9 \\
P-T5-L1350\# & 86.8 & 50.0 & 1.93 & 1349.4 & 67 & 181 & 201 & 6.9 \\
P-T5-L1900 & 86.8 & 50.0 & 1.93 & 1899.9 & 67 & 181 & 201 & 6.9 \\
P-T5-L2450 & 86.7 & 50.0 & 1.93 & 2449.7 & 67 & 181 & 201 & 6.9 \\
P-T5-L3000 & 86.9 & 50.0 & 1.93 & 3000.3 & 67 & 181 & 201 & 6.9 \\
P-T6-L300 & 86.8 & 50.0 & 1.94 & 299.8 & 65 & 227 & 253 & 6.3 \\
P-T6-L800 & 86.8 & 49.9 & 1.95 & 799.5 & 65 & 227 & 253 & 6.3 \\
P-T6-L1350 & 86.8 & 49.9 & 1.95 & 1349.9 & 65 & 227 & 253 & 6.3 \\
P-T6-L1900 & 86.8 & 50.0 & 1.95 & 1900.1 & 65 & 227 & 253 & 6.3 \\
P-T6-L1900\# & 86.7 & 50.0 & 1.93 & 1899.9 & 65 & 227 & 253 & 6.3 \\
P-T6-L2450 & 86.8 & 50.0 & 1.94 & 2449.8 & 65 & 227 & 253 & 6.3 \\
P-T6-L3000 & 86.8 & 50.0 & 1.94 & 3000.1 & 65 & 227 & 253 & 6.3 \\
\hline
\end{tabular}

Note: $H, B, t, B_{l}, L, E, f_{y}, f_{u}, f$ are the cross-section depth, cross-section width, cross-section thickness, stiffener length, column length, Young's modulus, $0.2 \%$ yield stress, material ultimate stress, and tensile strain at fracture, respectively. 
Table 2. The fabricated specimens and their material properties for lipped channel sections [15]

\begin{tabular}{lccccccccc}
\hline Specimens & $\begin{array}{c}H \\
(\mathrm{~mm})\end{array}$ & $\begin{array}{c}B \\
(\mathrm{~mm})\end{array}$ & $\begin{array}{c}t \\
(\mathrm{~mm})\end{array}$ & $\begin{array}{c}B_{l} \\
(\mathrm{~mm})\end{array}$ & $\begin{array}{c}L \\
(\mathrm{~mm})\end{array}$ & $\begin{array}{c}E \\
(\mathrm{GPa})\end{array}$ & $\begin{array}{c}f_{y} \\
(\mathrm{MPa})\end{array}$ & $\begin{array}{c}f_{u} \\
(\mathrm{MPa})\end{array}$ & $\begin{array}{c}\varepsilon_{f} \\
(\%)\end{array}$ \\
\hline L-T5-L300 & 80.1 & 40.0 & 1.56 & 15.0 & 300.2 & 63 & 175 & 186 & 7.2 \\
L-T5-L800 & 80.1 & 40.0 & 1.56 & 14.9 & 800.0 & 63 & 175 & 186 & 7.2 \\
L-T5-L1350 & 80.1 & 40.0 & 1.56 & 14.9 & 1349.7 & 63 & 175 & 186 & 7.2 \\
L-T5-L1350\# & 80.1 & 39.9 & 1.56 & 15.0 & 1349.6 & 63 & 175 & 186 & 7.2 \\
L-T5-L1900 & 80.1 & 40.1 & 1.56 & 15.0 & 1899.7 & 63 & 175 & 186 & 7.2 \\
L-T5-L2450 & 80.1 & 40.0 & 1.56 & 15.0 & 2450.2 & 63 & 175 & 186 & 7.2 \\
L-T5-L3000 & 80.1 & 40.0 & 1.56 & 14.9 & 2999.8 & 63 & 175 & 186 & 7.2 \\
L-T6-L300 & 80.0 & 40.0 & 1.56 & 15.0 & 299.9 & 62 & 239 & 250 & 7.4 \\
L-T6-L800 & 80.0 & 40.1 & 1.57 & 15.0 & 800.2 & 62 & 239 & 250 & 7.4 \\
L-T6-L1350 & 80.0 & 40.0 & 1.56 & 14.9 & 1350.1 & 62 & 239 & 250 & 7.4 \\
L-T6-L1900 & 80.1 & 40.1 & 1.55 & 15.1 & 1899.9 & 62 & 239 & 250 & 7.4 \\
L-T6-L1900\# & 80.1 & 40.1 & 1.57 & 15.1 & 1899.8 & 62 & 239 & 250 & 7.4 \\
L-T6-L2450 & 80.1 & 40.1 & 1.56 & 15.0 & 2450.1 & 62 & 239 & 250 & 7.4 \\
L-T6-L3000 & 80.1 & 40.0 & 1.56 & 15.0 & 2999.9 & 62 & 239 & 250 & 7.4 \\
\hline
\end{tabular}

Note: $H, B, t, B_{l}, L, E, f_{y}, f_{u}, f$ are the cross-section depth, cross-section width, cross-section thickness, stiffener length, column length, Young's modulus, $0.2 \%$ yield stress, material ultimate stress, and tensile strain at fracture, respectively. 
Table 3. Measured overall geometric imperfections at mid-length

\begin{tabular}{lclclclc}
\hline Specimens & $\delta \mathrm{y} / \mathrm{L}$ & Specimens & $\delta \mathrm{y} / \mathrm{L}$ & Specimens & $\delta \mathrm{y} / \mathrm{L}$ & Specimens & $\delta \mathrm{y} / \mathrm{L}$ \\
\hline P-T5-300 & --- & P-T6-300 & --- & L-T5-300 & --- & L-T6-300 & --- \\
P-T5-800 & $1 / 2109$ & P-T6-800 & $1 / 1533$ & L-T5-800 & $1 / 1325$ & L-T6-800 & $1 / 1551$ \\
P-T5-1350 & $1 / 1347$ & P-T6-1350 & $1 / 1656$ & L-T5-1350 & $1 / 1650$ & L-T6-1350 & $1 / 1818$ \\
P-T5-1350\# & $1 / 1576$ & P-T6-1900 & $1 / 1265$ & L-T5-1350\# & $1 / 1236$ & L-T6-1900 & $1 / 1240$ \\
P-T5-1900 & $1 / 1845$ & P-T6-1900\# & $1 / 1945$ & L-T5-1900 & $1 / 1517$ & L-T6-1900\# & $1 / 1600$ \\
P-T5-2450 & $1 / 1762$ & P-T6-2450 & $1 / 1649$ & L-T5-2450 & $1 / 1069$ & L-T6-2450 & $1 / 1808$ \\
P-T5-3000 & $1 / 1138$ & P-T6-3000 & $1 / 917$ & L-T5-3000 & $1 / 1333$ & L-T6-3000 & $1 / 1217$ \\
\hline
\end{tabular}


Table 4. The comparison between test strengths [15] and design strengths for plain channel sections

\begin{tabular}{|c|c|c|c|c|c|c|c|c|}
\hline Specimens & $\begin{array}{l}P_{E x p} \\
(k N)\end{array}$ & $\begin{array}{l}\text { Exp } \\
\text { failure } \\
\text { modes }\end{array}$ & $\frac{P_{E x p}}{P_{A A-1}}\left(\frac{P_{E x p}}{P_{A S / N Z S}}\right)$ & $\frac{P_{E x p}}{P_{A A-2}}$ & $\frac{P_{E x p}}{P_{E C 9}}$ & $\frac{P_{E x p}}{P_{C N}}$ & $\frac{P_{E x p}}{P_{N A S}}$ & $\frac{P_{E x p}}{P_{C S M}}$ \\
\hline P-T5-L300 & 41.6 & $\mathrm{~L}$ & $1.08(\mathrm{~L}+\mathrm{F})$ & 1.65 & $1.40(\mathrm{~F})$ & $1.80(\mathrm{~F})$ & $1.06(\mathrm{~L})$ & 1.08 \\
\hline P-T5-L800 & 37.4 & $\mathrm{~L}$ & $1.08(\mathrm{~L}+\mathrm{F})$ & 1.49 & $1.39(\mathrm{~F})$ & $1.80(\mathrm{~F})$ & $1.13(\mathrm{~L})$ & 0.97 \\
\hline P-T5-L1350 & 33.5 & $\mathrm{~L}+\mathrm{F}$ & $1.17(\mathrm{~L}+\mathrm{F})$ & - & $1.47(\mathrm{~F})$ & $1.86(\mathrm{~F})$ & $1.16(\mathrm{~L}+\mathrm{F})$ & - \\
\hline P-T5-L1350\# & 31.9 & $\mathrm{~L}+\mathrm{F}$ & $1.11(\mathrm{~L}+\mathrm{F})$ & - & $1.40(\mathrm{~F})$ & $1.76(\mathrm{~F})$ & $1.22(\mathrm{~L}+\mathrm{F})$ & - \\
\hline P-T5-L1900 & 26.5 & $\mathrm{~L}+\mathrm{F}$ & $1.16(\mathrm{~L}+\mathrm{F})$ & - & $1.50(\mathrm{~F})$ & $1.68(\mathrm{~F})$ & $1.29(\mathrm{~L}+\mathrm{F})$ & - \\
\hline P-T5-L2450 & 23.1 & $\mathrm{~L}+\mathrm{F}+\mathrm{FT}$ & $1.20(\mathrm{~F})$ & - & $1.79(\mathrm{~F})$ & $1.70(\mathrm{~F})$ & $1.23(\mathrm{~L}+\mathrm{F})$ & - \\
\hline P-T5-L3000 & 16.2 & $\mathrm{~L}+\mathrm{F}+\mathrm{FT}$ & $0.96(\mathrm{~F})$ & - & $1.70(\mathrm{~F})$ & $1.38(\mathrm{~F})$ & $1.41(\mathrm{~L}+\mathrm{F})$ & - \\
\hline P-T6-L300 & 45.4 & L & $1.11(\mathrm{~L}+\mathrm{F})$ & 1.61 & $1.22(\mathrm{~F})$ & $1.63(\mathrm{~F})$ & $1.10(\mathrm{~L})$ & 0.94 \\
\hline P-T6-L800 & 41.3 & $\mathrm{~L}$ & $1.13(\mathrm{~L}+\mathrm{F})$ & 1.45 & $1.25(\mathrm{~F})$ & $1.58(\mathrm{~F})$ & $1.16(\mathrm{~L})$ & 0.85 \\
\hline P-T6-L1350 & 34.4 & $\mathrm{~L}+\mathrm{F}$ & $1.21(\mathrm{~L}+\mathrm{F})$ & - & $1.29(\mathrm{~F})$ & $1.46(\mathrm{~F})$ & $1.25(\mathrm{~L}+\mathrm{F})$ & - \\
\hline P-T6-L1900 & 27.0 & $\mathrm{~L}+\mathrm{F}$ & $1.19(\mathrm{~L}+\mathrm{F})$ & - & $1.39(\mathrm{~F})$ & $1.27(\mathrm{~F})$ & $1.34(\mathrm{~L}+\mathrm{F})$ & - \\
\hline P-T6-L1900\# & 25.9 & $\mathrm{~L}+\mathrm{F}$ & $1.16(\mathrm{~L}+\mathrm{F})$ & - & $1.35(\mathrm{~F})$ & $1.23(\mathrm{~F})$ & $1.39(\mathrm{~L}+\mathrm{F})$ & - \\
\hline P-T6-L2450 & 23.2 & $\mathrm{~L}+\mathrm{F}+\mathrm{FT}$ & $1.22(\mathrm{~F})$ & - & $1.72(\mathrm{~F})$ & $1.24(\mathrm{~F})$ & $1.23(\mathrm{~L}+\mathrm{F})$ & - \\
\hline P-T6-L3000 & 18.6 & $\mathrm{~L}+\mathrm{F}+\mathrm{FT}$ & $1.13(\mathrm{~F})$ & - & $1.92(\mathrm{~F})$ & $1.14(\mathrm{~F})$ & $1.18(\mathrm{~L}+\mathrm{F})$ & - \\
\hline Mean, & - & - & 1.14 & - & 1.49 & 1.54 & 1.23 & - \\
\hline $\mathrm{COV}$ & - & - & 0.061 & - & 0.145 & 0.161 & 0.085 & - \\
\hline
\end{tabular}

Note: 'L' represents local buckling; 'F' represents flexural buckling; 'FT' represents flexural-torsional buckling 
Table 5. The comparison between test strengths [15] and design strengths for lipped channel sections

\begin{tabular}{|c|c|c|c|c|c|c|c|c|}
\hline Specimens & $\begin{array}{l}P_{E x p} \\
(k N)\end{array}$ & $\begin{array}{c}\text { Exp } \\
\text { Failure } \\
\text { mode }\end{array}$ & $\frac{P_{\text {Exp }}}{P_{A A-1}}\left(\frac{P_{E x p}}{P_{A S / N Z S}}\right)$ & $\frac{P_{E x p}}{P_{A A-2}}$ & $\frac{P_{E x p}}{P_{E C 9}}$ & $\frac{P_{E x p}}{P_{C N}}$ & $\frac{P_{E x p}}{P_{N A S}}$ & $\frac{P_{E x p}}{P_{C S M}}$ \\
\hline L-T5-L300 & 42.2 & $\mathrm{~L}$ & $1.35(\mathrm{~L}+\mathrm{F})$ & 1.38 & $1.44(\mathrm{~F})$ & $1.56(\mathrm{~F})$ & $1.22(\mathrm{~L})$ & 1.40 \\
\hline L-T5-L800 & 39.4 & $\mathrm{~L}$ & $1.40(\mathrm{~L}+\mathrm{F})$ & 1.30 & $1.48(\mathrm{~F})$ & $1.66(\mathrm{~F})$ & $1.26(\mathrm{~L})$ & 1.31 \\
\hline L-T5-L1350 & 35.3 & $\mathrm{~L}+\mathrm{FT}$ & $1.48(\mathrm{~L}+\mathrm{F})$ & - & $1.54(\mathrm{~F})$ & $1.73(\mathrm{~F})$ & $1.34(\mathrm{~L}+\mathrm{F})$ & - \\
\hline L-T5-L1350\# & 32.1 & $\mathrm{~L}+\mathrm{FT}$ & $1.34(\mathrm{~L}+\mathrm{F})$ & - & $1.40(\mathrm{~F})$ & $1.56(\mathrm{~F})$ & $1.21(\mathrm{~L}+\mathrm{F})$ & - \\
\hline L-T5-L1900 & 26.0 & $\mathrm{~L}+\mathrm{FT}$ & $1.37(\mathrm{~L}+\mathrm{F})$ & - & $1.43(\mathrm{~F})$ & $1.49(\mathrm{~F})$ & $1.24(\mathrm{~L}+\mathrm{F})$ & - \\
\hline L-T5-L2450 & 16.9 & FT & $1.05(\mathrm{~L}+\mathrm{F})$ & - & $1.24(\mathrm{~F})$ & $1.18(\mathrm{~F})$ & $0.95(\mathrm{~L}+\mathrm{F})$ & - \\
\hline L-T5-L3000 & 12.8 & FT & $0.91(\mathrm{~L}+\mathrm{F})$ & - & $1.27(\mathrm{~F})$ & $1.11(\mathrm{~F})$ & $0.82(\mathrm{~L}+\mathrm{F})$ & - \\
\hline L-T6-L300 & 50.4 & $\mathrm{~L}$ & $1.47(\mathrm{~L}+\mathrm{F})$ & 1.40 & $1.27(\mathrm{~F})$ & $1.56(\mathrm{~F})$ & $1.33(\mathrm{~L})$ & 1.22 \\
\hline L-T6-L800 & 48.8 & $\mathrm{~L}$ & $1.59(\mathrm{~L}+\mathrm{F})$ & 1.35 & $1.38(\mathrm{~F})$ & $1.64(\mathrm{~F})$ & $1.44(\mathrm{~L})$ & 1.18 \\
\hline L-T6-L1350 & 42.9 & $\mathrm{~L}+\mathrm{FT}$ & $1.80(\mathrm{~L}+\mathrm{F})$ & - & $1.49(\mathrm{~F})$ & $1.62(\mathrm{~F})$ & $1.62(\mathrm{~L}+\mathrm{F})$ & - \\
\hline L-T6-L1900 & 27.1 & $\mathrm{~L}+\mathrm{FT}$ & $1.44(\mathrm{~L}+\mathrm{F})$ & - & $1.29(\mathrm{~F})$ & $1.17(\mathrm{~F})$ & $1.30(\mathrm{~L}+\mathrm{F})$ & - \\
\hline L-T6-L1900\# & 27.0 & $\mathrm{~L}+\mathrm{FT}$ & $1.42(\mathrm{~L}+\mathrm{F})$ & - & $1.28(\mathrm{~F})$ & $1.16(\mathrm{~F})$ & $1.28(\mathrm{~L}+\mathrm{F})$ & - \\
\hline L-T6-L2450 & 17.4 & FT & $1.09(\mathrm{~L}+\mathrm{F})$ & - & $1.18(\mathrm{~F})$ & $0.92(\mathrm{~F})$ & $0.98(\mathrm{~L}+\mathrm{F})$ & - \\
\hline L-T6-L3000 & 13.2 & FT & $1.10(\mathrm{~L}+\mathrm{F})$ & - & $1.25(\mathrm{~F})$ & $0.91(\mathrm{~F})$ & $0.85(\mathrm{~L}+\mathrm{F})$ & - \\
\hline Mean, & - & - & 1.34 & - & 1.35 & 1.38 & 1.20 & - \\
\hline $\mathrm{COV}$ & - & - & 0.175 & - & 0.082 & 0.208 & 0.188 & - \\
\hline
\end{tabular}

Note: 'L' represents local buckling; 'F' represents flexural buckling; 'FT' represents flexural-torsional buckling 
Table 6. The comparison between ultimate strengths and design strengths for plain channel section columns (14 tests data $\& 50$ FE data)

\begin{tabular}{|c|c|c|c|c|c|c|c|}
\hline \multirow{2}{*}{ Tests: 14 \& FEA: 50} & $P_{u}$ & $P_{u}$ & $P_{u}$ & $P_{u}$ & $P_{u}$ & $P_{u}$ & $P_{u}$ \\
\hline & $\overline{P_{A A-1}}$ & $\overline{P_{A A-2}}$ & $\overline{P_{A S / N Z S}}$ & $\overline{P_{E C 9}}$ & $\overline{P_{C N}}$ & $\overline{P_{N A S}}$ & $\overline{P_{C S M}}$ \\
\hline Mean & 1.20 & 1.42 & 1.20 & 1.32 & 1.63 & 1.01 & 1.01 \\
\hline $\mathrm{COV}$ & 0.145 & 0.093 & 0.145 & 0.188 & 0.196 & 0.137 & 0.072 \\
\hline Resistance factor & 0.85 & 0.85 & 0.85 & 0.91 & 0.83 & 0.85 & 0.85 \\
\hline Reliability index & 2.73 & 3.81 & 2.74 & 2.54 & 3.34 & 2.18 & 2.61 \\
\hline
\end{tabular}


Table 7. The comparison between ultimate strengths and design strengths for lipped channel section columns (14 tests data \& 50 FE data)

\begin{tabular}{|c|c|c|c|c|c|c|c|}
\hline \multirow{2}{*}{ Tests: $14 \&$ FEA: 50} & $P_{u}$ & $P_{u}$ & $P_{u}$ & $P_{u}$ & $P_{u}$ & $P_{u}$ & $P_{u}$ \\
\hline & $P_{A A-1}$ & $P_{A A-2}$ & $P_{A S / N Z S}$ & $P_{E C 9}$ & $\overline{P_{C N}}$ & $P_{N A S}$ & $P_{C S M}$ \\
\hline Mean, & 1.59 & 1.30 & 1.59 & 1.41 & 1.61 & 1.09 & 1.10 \\
\hline $\mathrm{COV}$ & 0.278 & 0.222 & 0.278 & 0.206 & 0.252 & 0.175 & 0.129 \\
\hline Resistance factor, & 0.85 & 0.85 & 0.85 & 0.91 & 0.83 & 0.85 & 0.85 \\
\hline Reliability index, & 2.54 & 2.41 & 2.56 & 2.61 & 2.82 & 2.20 & 2.58 \\
\hline
\end{tabular}

